\title{
Research on the Interaction between Sphalerite and Silica Particles with Different Calcium Ion Solutions
}

\author{
Hao Ren ${ }^{1 *}$, Mengqi Ren ${ }^{2}$, Jing Ning ${ }^{3}$, Zhen $\mathrm{Li}^{3}$ \\ ${ }^{1}$ Key Laboratory of Chemical Sensing \& Analysis in Universities of Shandong, School of Chemistry and \\ Chemical Engineering, University of Jinan, Shandong, China \\ ${ }^{2}$ School of Chemical Engineering and Technology, Tianjin University, Tianjin, China \\ ${ }^{3}$ School of Chemistry and Chemical Engineering, University of Jinan, Shandong, China \\ Email: *rhjf@163.com, renmengqi@126.com, serenening@qq.com,1z_646699@126.com
}

Received May 19, 2013; revised June 20, 2013; accepted June 27, 2013

Copyright (C) 2013 Hao Ren et al. This is an open access article distributed under the Creative Commons Attribution License, which permits unrestricted use, distribution, and reproduction in any medium, provided the original work is properly cited.

\begin{abstract}
The interactions among fine particles are unavoidable in solutions, and the strong particle interactions have a negative impact on mineral separations. How to reduce and prevent the agglomeration of particles is one of the important challenges facing production and research. The interactions of sphalerite and silica particles were studied with variation of calcium ions solutions. Zeta potential measurement and a novel Zeta potential distribution (ZPD) measurement method were used in this paper. The phenomena of mineral coagulation and absorption of flotation reagent were analyzed in solutions of different $\mathrm{pH}$ and calcium ion concentration.
\end{abstract}

Keywords: Sphalerite; Silica; Interaction; Zeta Potential; Flotation Reagent

\section{Introduction}

In complex sulphide ores, the fine mineral particles have very significant interactions after adsorption of calcium ions from the gypsum supersaturated solution, and thus have a negative effect on flotation separation [1]. The key to solving this problem is to take appropriate measures to reduce or eliminate calcium ions, prevent the interaction among fine mineral particles. The flotation efficiency is improved when flotation reagent selectively adsorbs on mineral surfaces.

The acidic process water has been discharged from sulphide flotation for a long time.

It is reported that gypsum may precipitate on sphalerite and silica surfaces in flotation process, and the dissociated calcium ions adsorbed on the particle surfaces which decreased reagent selectivity and flotation recovery. Therefore, fouling is generated in the inner wall of pipeline, and this negatively affects the industrial process.

The strength of particle interaction is directly related to the reagent absorption on mineral surface. This paper investigated the effects of calcium ions on particle interactions in solutions with different concentrations of cal-

"Corresponding author. cium ions by measuring the Zeta-potential and Zeta-potential distribution and the effect of calcium ions on the interaction between particles in different backgrounds by the Zeta-potential distribution measurement method.

\section{Basic Ideas}

As shown in Figure 1, the ZPD for a binary particulate component system that can be interpreted for particle interactions. In this figure, the black and white circles represent sphalerite (C) and silica (M) particles, respectively. 1) superimposed ZPD of the two components measured separately; 2) a binary mixture without attraction; 3 ) weak reaction (silica partially covered with sphalerite particles); 4) strong reaction (silica fully covered with sphalerite and with remnant free sphalerite particles); 5) strong reaction (silica fully covered with sphalerite without remnant free sphalerite particles) [2].

The concept of measuring zeta potential distributions (ZPD) was proposed by Prof. Xu's research team back to $2003[3,4]$. This method can directly study particle interactions and slime coating phenomenon using individual components and their mixture as illustrated in Figure 1. For a binary particulate component system of sphalerite (Sp) and silica (Si) suspension, for example, ZPD of individual component can be measured separately and 

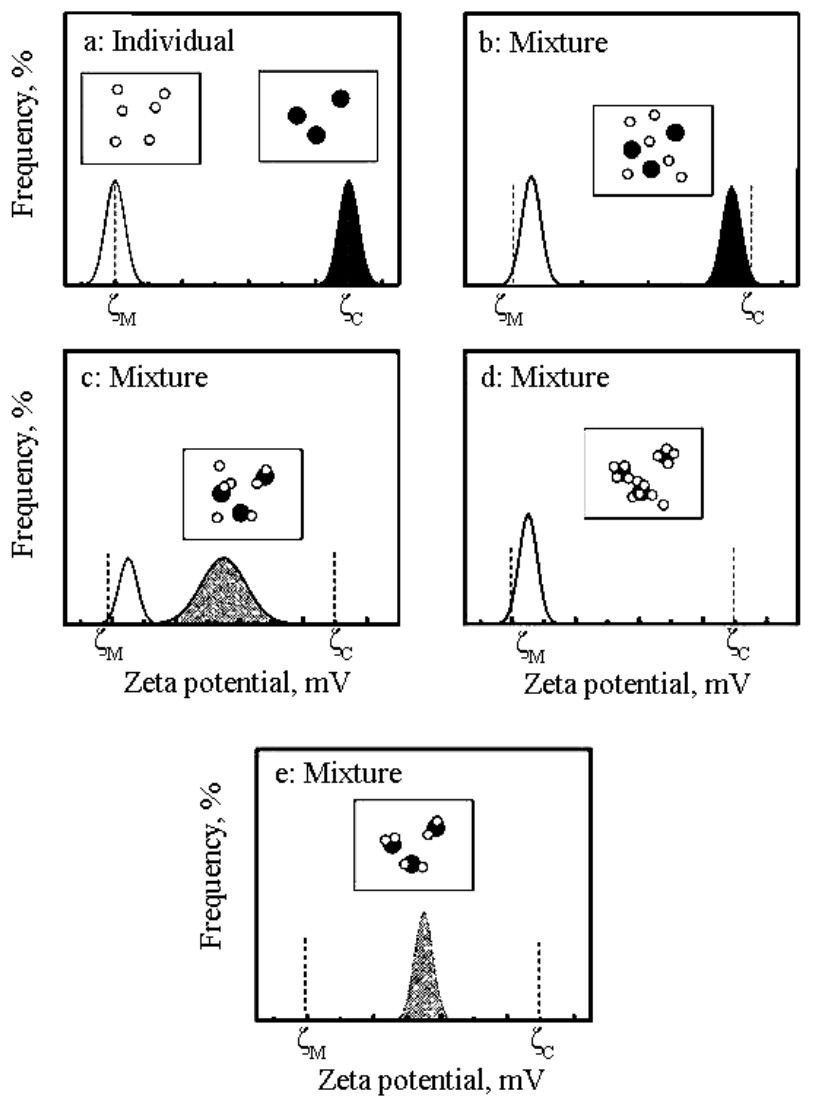

Figure 1. Zeta potential distributions (ZPD).

assumed to be centered at $\xi_{\mathrm{Sp}}$ and $\xi_{\mathrm{Si}}$, respectively. Their interactions can be interpreted by the result of ZPD when the binary particulate component is mixed together under the same physicochemical conditions.

\section{Materials and Procedure}

\subsection{Reagents}

Calcium sulfate dihydrate, calcium carbonate, potassium chloride, nitric acid, and sodium hydroxide were analytical grade and were purchased from Sinopharm Chemical Reagent Co., Ltd.

\subsection{Mineral Preparation}

The natural sphalerite, provided by Ward's Natural Science, has $60.33 \% \mathrm{Zn}, 11.65 \% \mathrm{Fe}$ and $28.02 \% \mathrm{~S}$ based on atomic adsorption spectrophotometry analysis. The sample was dry crushed in a ring pulveriser, screened to obtain two size fractions -325 mesh fine and +325 mesh coarse, and then stored them in a freezer at $-10^{\circ} \mathrm{C}$. The $99.50 \%$ pure fine silica ( $-325 \mathrm{mesh}$ ) was purchased from Sinopharm Chemical Reagent Co., Ltd.

\subsection{Instruments}

Zeta potential was measured using Zeta PALS which was purchased from USA Brook Haven Instrument Company. Zeta potential distributions (ZPD) were obtained using a SEPHY/CAD Zetaphorometer III which was made in France.

\subsection{Zeta-Potential}

\subsubsection{Fundamental}

Zeta potential distribution measurement was carried out using a Zetaphoremeter III (SEPHY/CAD) which was equipped with a rectangular electrophoresis cell containing a pair of hydrogenated palladium electrodes, a laser-illuminator and a digital video image capture (CCD camera) as shown in Figure 2. The computerized operating system allowed an accurate positioning of camera view field at a stationary layer to achieve accurate measurement of electrophoretic mobility. About $40 \mathrm{ml}$ of the prepared suspension was used to fill the electrophoresis cell. Through the laser-illuminating and video-viewing system, the movement of 50 - 100 particles in the stationary layer was traced, five times for each direction by alternating positive and negative electrode potentials (as shown in Figure 3). The conductivity and $\mathrm{pH}$ of the suspension were monitored continuously during the measurement [2]. In this study, the environmental temperature was maintained at $20^{\circ} \mathrm{C} \pm 0.1^{\circ} \mathrm{C}$.

\subsubsection{Individual Mineral and Mixture}

A suspension containing about $0.1 \mathrm{wt} \%$ mineral was prepared in $1 \mathrm{mM} \mathrm{KCl}$ solution and conditioned by magnetic stirring for 5 minutes. The upper portion of this suspension was taken for zeta potential distribution measurement after settling for 10 minutes. The binary sphalerite/silica mixture suspension was prepared by mixing equal volume of the prepared sphalerite and silica sus-

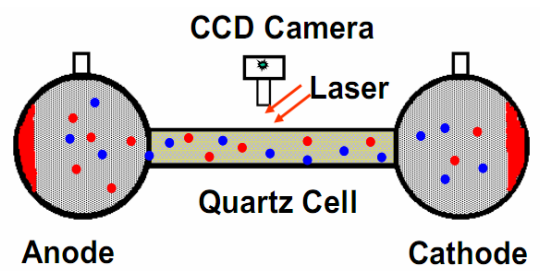

Figure 2. Zetaphoremeter III (SEPHY/CAD).

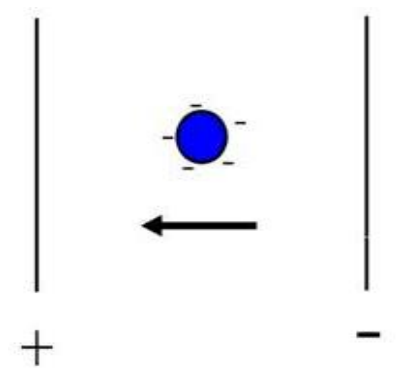

Figure 3. The particle in electric field. 
pensions and conditioning in an ultrasonic bath for 10 minutes [4].

\section{Experimental}

\subsection{Adsorption of Calcium Ions}

As shown in Figures $\mathbf{4}$ and 5, the adsorption of calcium ions as a function of $\mathrm{pH}$ in gypsum and calcium carbonate supersaturated solutions. These two figures indicate that the adsorption of calcium ions was different with variation of calcium ions concentrations. The adsorption of dispersed particles on the interface is affected by some factors, such as surface area, solution $\mathrm{pH}$, etc.

Figures 4 and 5 show the adsorption of calcium ions as a function of $\mathrm{pH}$ in gypsum and calcium carbonate supersaturated solutions. These two figures indicate that the adsorption of calcium ions was different with variation of calcium ions concentrations. The adsorption of

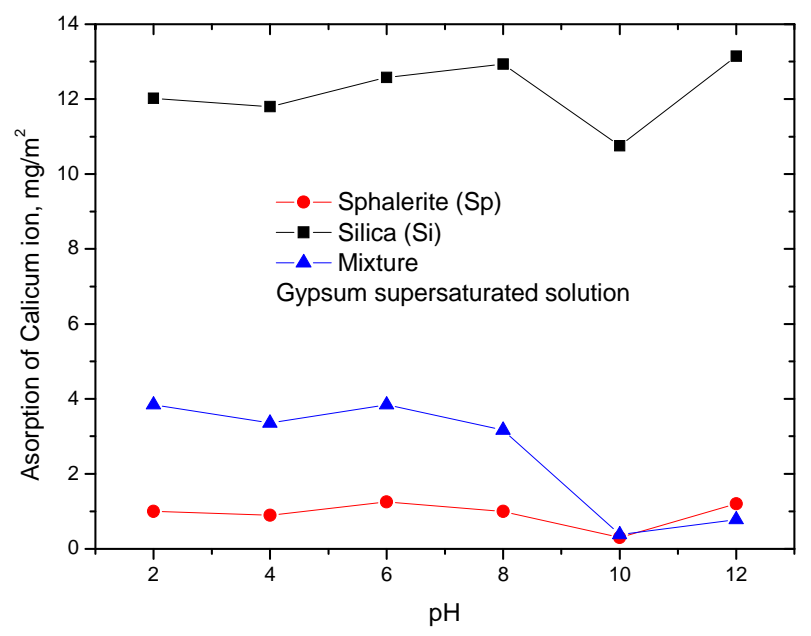

Figure 4. The adsorption of calcium ion as a function of $\mathrm{pH}$ in gypsum supersaturated solution.

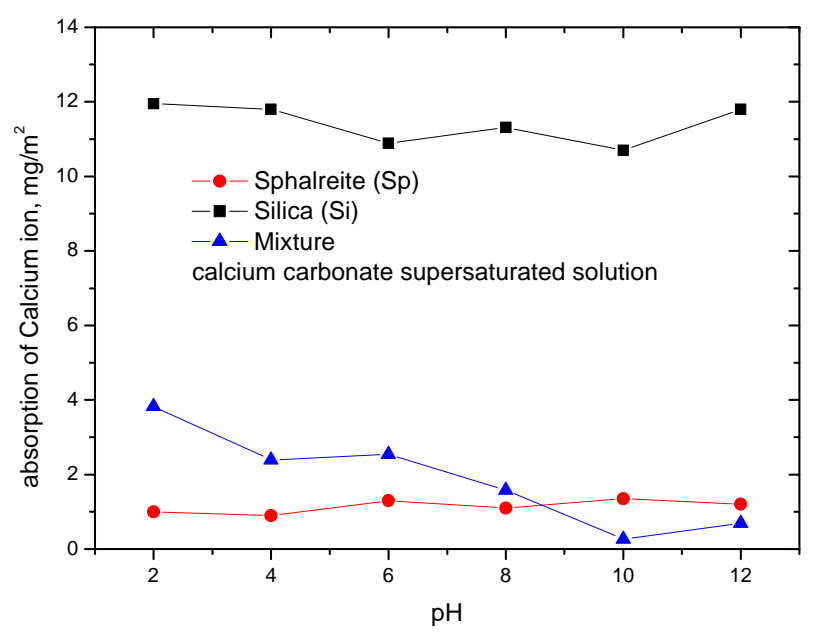

Figure 5. The adsorption of calcium ion as a function of $\mathrm{pH}$ in calcium carbonate supersaturated solution. dispersed particles on the interface is affected by some factors, such as surface area, solution $\mathrm{pH}$, etc.

\subsection{Zeta Potential and Zeta Potential Distribution (ZPD)}

As shown in Figure 6(a), the effects of solution $\mathrm{pH}$ on Zeta potential of individual components (sphalerite or silica) and their mixture ( $\mathrm{Si}: \mathrm{Sp}=4: 1)$. This figure clearly indicates that Zeta potential had the same trend for individual components and the mixture with increasing of solution $\mathrm{pH}$ in gypsum supersaturated solution, but Zeta potential of mixture was between two individual minerals and was subject to fluctuation of the solution $\mathrm{pH}$. Based on results of Figure 6, the following Zeta potential difference was calculated for sphalerite and silicate at $\mathrm{pH} 9.0$.

Genernally, the dividing line between stable and unstable suspensions is taken at either $+30 \mathrm{mV}$ or $-30 \mathrm{mV}$. Particles with zeta potential more positive than $+30 \mathrm{mV}$ or more negative than $-30 \mathrm{mV}$ are normally considered stable. In other words, a well dispersed suspension consists of individual, separated particles, and is stabilized by repulsive inter-particle forces when the absolute values of zeta potential are higher than $30 \mathrm{mV}$. This means that the interactions are relatively weak among the particles, and which is favorable to the flotation reagent adsorption.

There exist strong particle interactions at $\mathrm{pH} 2.5-3.5$ according to Figure 1(d) and Figure 6(a) results. Silica particles were partially covered by sphalerite particles, and there was possibly some remnant free sphalerite particles in the solution. At pH 3.5 - 11.0, sphalerite particles were partially coated by silica particles and left some free silica particles in the solution. As a result, strong attraction by Figure 1(d) when ZPD is illustrated at $\mathrm{pH}$ 3.5 - 11.0, sphalerite partially covered with and possibly with some remnant free Silica particles, flotation reagent cannot selectively adsorb on the surface of sphalerite and this reduced the flotation separation efficiency $[5,6]$.

Compared with Figures 6 and $\mathbf{7}$ had a very similar pattern of Zeta potential curve in calcium carbonate supersaturated solution. The Zeta potential of silica fluctuated with increasing the solution pH. Figure 7 also indicates that there was a Zeta potential overlap of sphalerite and mixture at $\mathrm{pH} 8.5-12$. Below is the calculation of Zeta potential difference of sphalerite, silica and mixture at $\mathrm{pH} 9.0$.

As shown in Figure 7, $\Delta \xi_{0}, \Delta \xi_{1}$ and $\Delta \xi_{2}$ are $14.3 \mathrm{mV}$, $11.3 \mathrm{mV}$ and $3.0 \mathrm{mV}$ at $\mathrm{pH} 9.0$, respectively. The interaction between minerial particles is vevy significant.

The ZPD of mixture also suggests that the interactions were very strong among different particles at $\mathrm{pH} 2.5$ - 8.0 and the silica was partially covered by sphalerite particles. At pH 8.0 - 10.0, mixture and sphalerite particles 


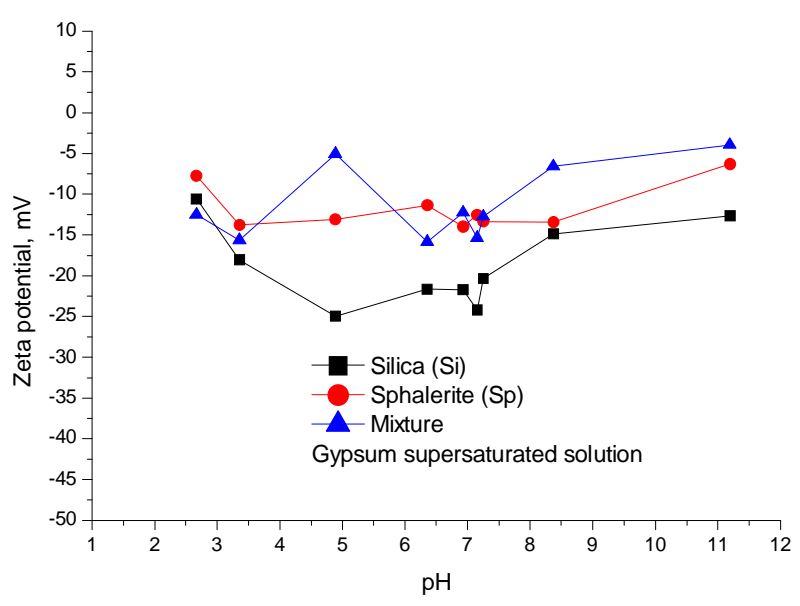

(a)

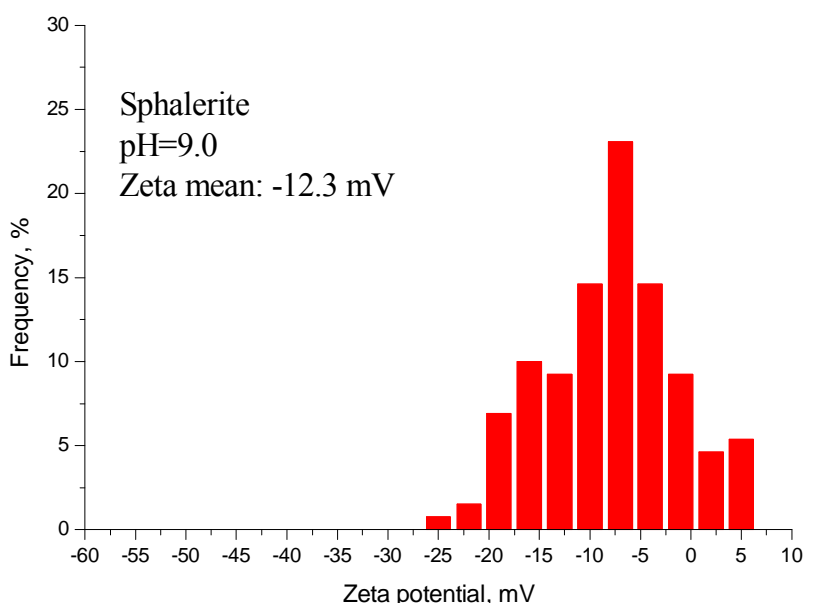

(c)

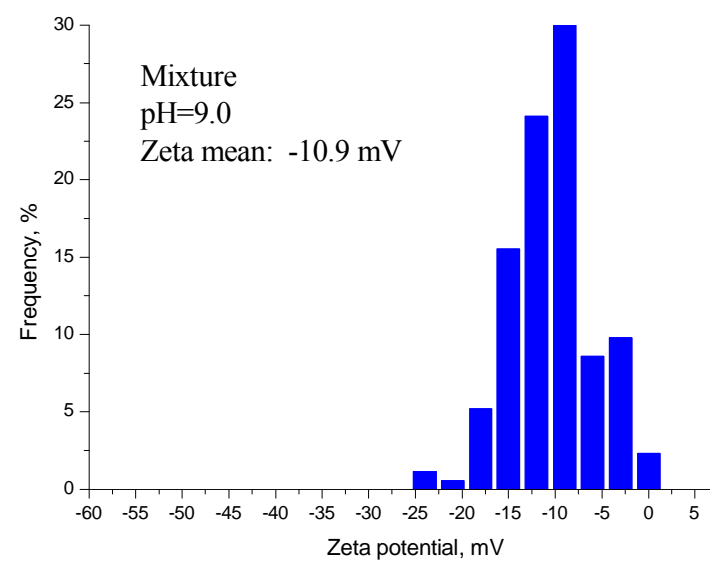

(b)

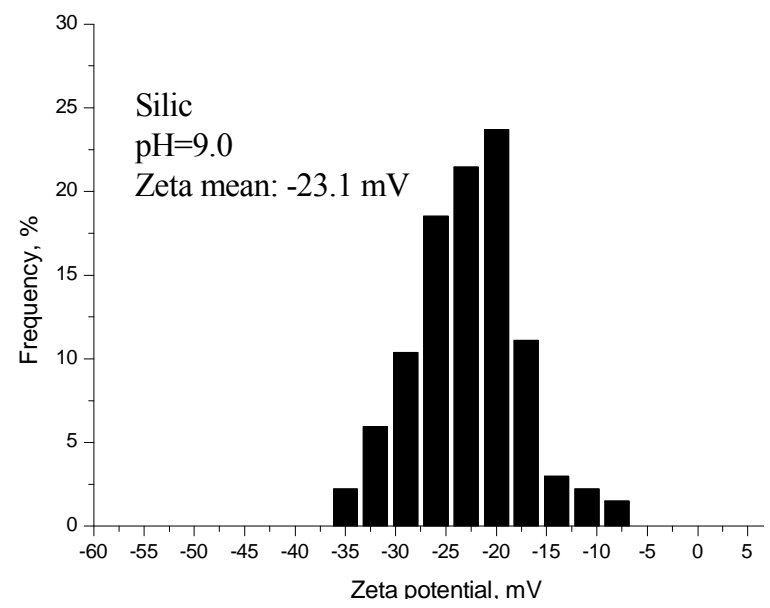

(d)

Figure 6. (a) Zeta potential of individual and mixture as a function of pH in gypsum supersaturated solution; (b), (c), (d) ZPD of mixture, sphalerite and silica suspensions containing gypsum supersaturated solution measured at pH 9.0, separately.

had the overlap Zeta potential. With and possibly with some remnant free silica particles; the Zeta potential of mixture and sphalerite is overlap as $\mathrm{pH}$ was $8.0-10.0$, as shown by Figure 1(d). This significantly reduced the flotation reagent selectivity as a result of symbiotic association among sphalerite and silica particles there is a significant interaction as the agglomeration took place between heterogeneous particles, sphalerite fully covered with and possibly with some remnant free silica particles, flotation reagent can not be adsorbed selectively on the surface of silica. There will be seriously intergrowth inclusion phenomenon in flotation $[5,6]$. This conclusion coincides with the Figure 1(d) results.

The effects of solution $\mathrm{pH}$ on Zeta potential in $1 \mathrm{mM}$ $\mathrm{KCl}$ solution is shown in Figure 8. It is clear that the Zeta potentials of individual and mixture decreased with increasing (sphalerite or silica) and mixture $(\mathrm{Si}: \mathrm{Sp}=4: 1)$ was decreased with increasing of $\mathrm{pH}$ in $1 \mathrm{mM}$ the $\mathrm{KCl}$ solution. The Zeta potential of mixture fell somewhere between these two individual minerals and there exist strong reactions at $\mathrm{pH} 2.0-9.5$. Silica particles were fully covered with sphalerite without remnant free sphalerite particles and this is in good agreement with Figure 1(e) Zeta potential measurement. ZPD of mixture is illustrated at $\mathrm{pH} 2-9.5$.

\section{SEM Micrograph and EDS}

\subsection{Silica Micrograph}

As shown in Figure 9(c) and Table 1, surface precipitation was occurring on silica surface and probably the specie was copper xanthate as illustrated at Figure 9(c) point 1 and point 3. Figure 9(c) point 2 shows the electron microscopy of silica surface and no copper xanthate appeared, therefore there were no $\mathrm{S}$ and $\mathrm{Cu}$ ingredients on the surface. The reagent concentration was relatively lower on silica surface because element $\mathrm{S}$ was mainly from xanthate and its ingredient was only $3.19 \mathrm{wt} \%$ $3.29 \mathrm{wt} \%$, element $\mathrm{Cu}$ was mainly from cooper sulfate with the ingredient of $7.04 \mathrm{wt} \%-9.52 \mathrm{wt} \%$. 


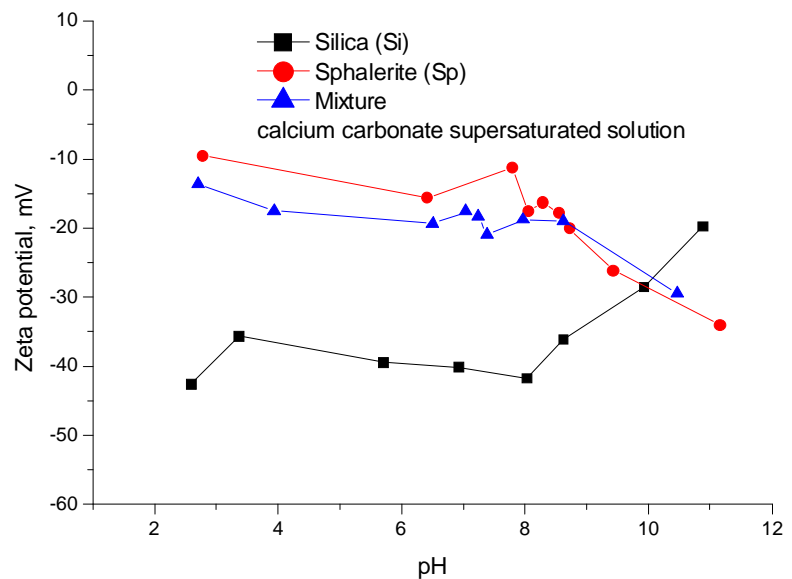

(a)

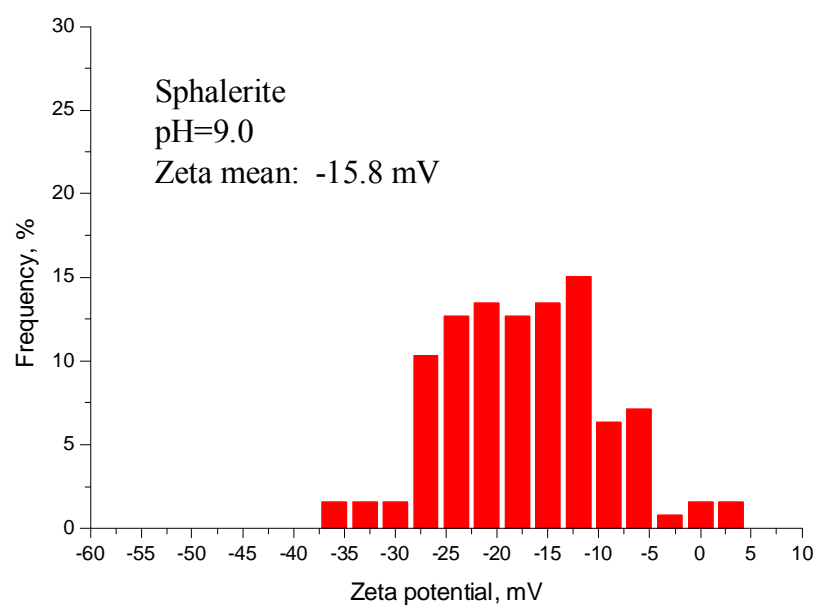

(c)

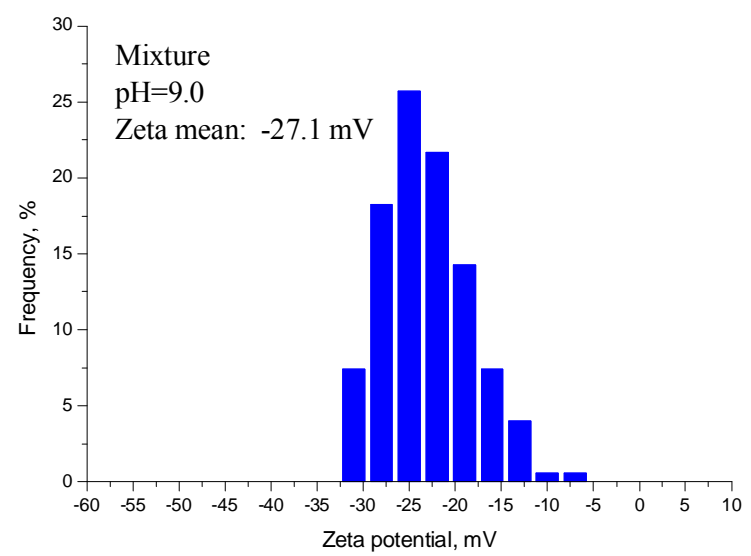

(b)

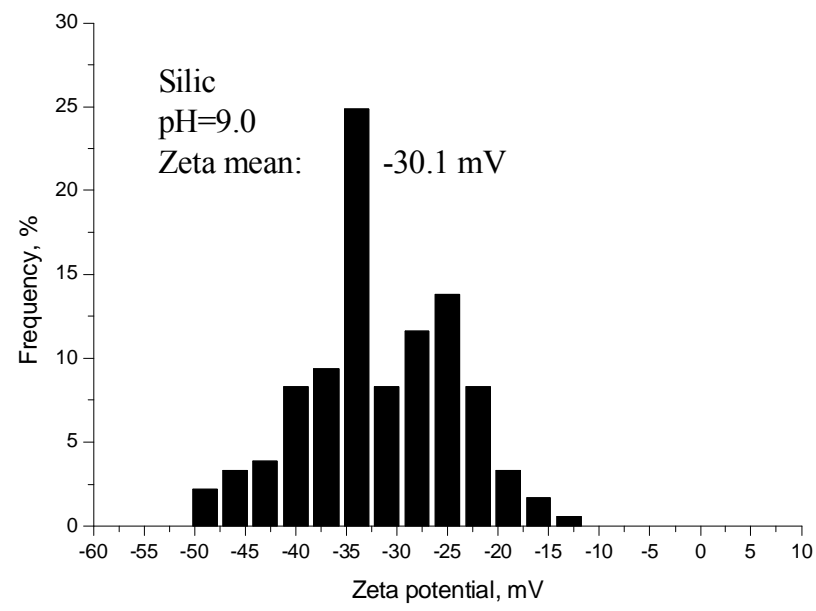

(d)

Figure 7. (a) Zeta potential of individual and mixture as a function of $\mathrm{pH}$ in calcium carbonate supersaturated solution; (b), (c), (d) ZPD of mixture, sphalerite and silica suspensions in calcium carbonate supersaturated solution at pH 9.0.

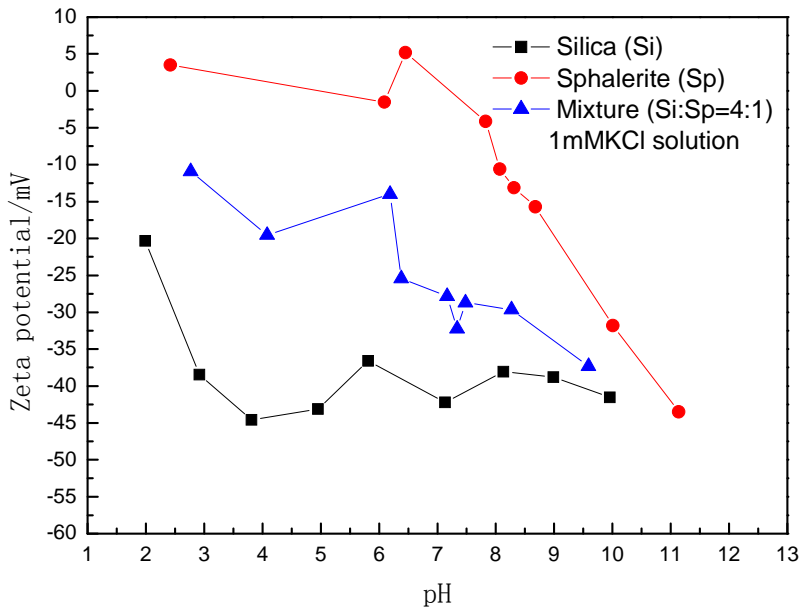

Figure 8. Zeta potential of individual and mixture as a function of $\mathrm{pH}$ in $1 \mathrm{mM} \mathrm{KCl}$ solution.

\subsection{Sphalerite}

The SEM image and EDS give the evidence of precipita- tion on sphalerite surface at pH 9 (Figures 10(b) and (c)) and the species were probably copper xanthate. Monocoagulation and heterocoagulation were probably the contributors to the presence of precipitation on sphalerite surface at pH 3 - 11 as indicated in Figure 10(a). Over the range $\mathrm{pH} 3-11$ possibly contributes to the presence of precipitates on the sphalerite surface (see Figure 10(a)).

Based on the information provided in Figure 10(c) and Table 2, a lot of copper xanthate species were generated on sphalerite surface as indicated at Figure 10(c) point 1 and point 3 . However, no copper xanthate species were found at Figure 10(c) point 2. This explained that there was no $\mathrm{Cu}$ ingredient on sphalerite surface, but the element $\mathrm{S}$ content was up to $28.90 \mathrm{wt} \%$ at point 2 . This also reflected that sphalerite itself contains a higher component $\mathrm{S}$. The reagent concentration is relatively higher on the sphalerite surface than that on the silica surface after reagent adsorption. Content of element $\mathrm{S}$ and $\mathrm{Cu}$ was $20.62 \mathrm{wt} \%-21.27 \mathrm{wt} \%$ and $9.46 \mathrm{wt} \%$ - 
Table 1. Element concentration and weight percentage.

\begin{tabular}{|c|c|c|c|c|c|c|c|c|c|}
\hline \multirow{3}{*}{ Silica } & & \multicolumn{2}{|c|}{ Before treated } & \multicolumn{6}{|c|}{ After treated } \\
\hline & & \multirow[t]{2}{*}{ Element concentration } & \multirow[t]{2}{*}{ Weight (\%) } & \multicolumn{3}{|c|}{ Element concentration } & \multicolumn{3}{|c|}{ Weight $(\%)$} \\
\hline & & & & Point 1 & Point 2 & Point 3 & Point 1 & Point 2 & Point 3 \\
\hline \multirow{2}{*}{ Figure 9(c) } & $\mathrm{S}$ & 0 & 0 & 0.29 & 0 & 0.26 & 3.29 & 0 & 3.19 \\
\hline & $\mathrm{Cu}$ & 0 & 0 & 0.53 & 0 & 0.35 & 9.52 & 0 & 7.04 \\
\hline
\end{tabular}

Table 2. Element concentration and weight percentage.

\begin{tabular}{|c|c|c|c|c|c|c|c|c|c|}
\hline \multirow[b]{2}{*}{ Sphalerite } & & \multicolumn{2}{|c|}{ Before treated } & \multicolumn{6}{|c|}{ After treated } \\
\hline & & Element Concentration & Weight (\%) & \multicolumn{3}{|c|}{ Element concentration } & \multicolumn{3}{|c|}{ Weight (\%) } \\
\hline \multirow{2}{*}{ Figure 10(c) } & $\mathrm{S}$ & 3.53 & 33.73 & 4.18 & 4.35 & 4.08 & 20.62 & 28.90 & 21.27 \\
\hline & $\mathrm{Cu}$ & 0 & 0 & 1.47 & 0 & 1.57 & 9.46 & 0 & 10.86 \\
\hline
\end{tabular}
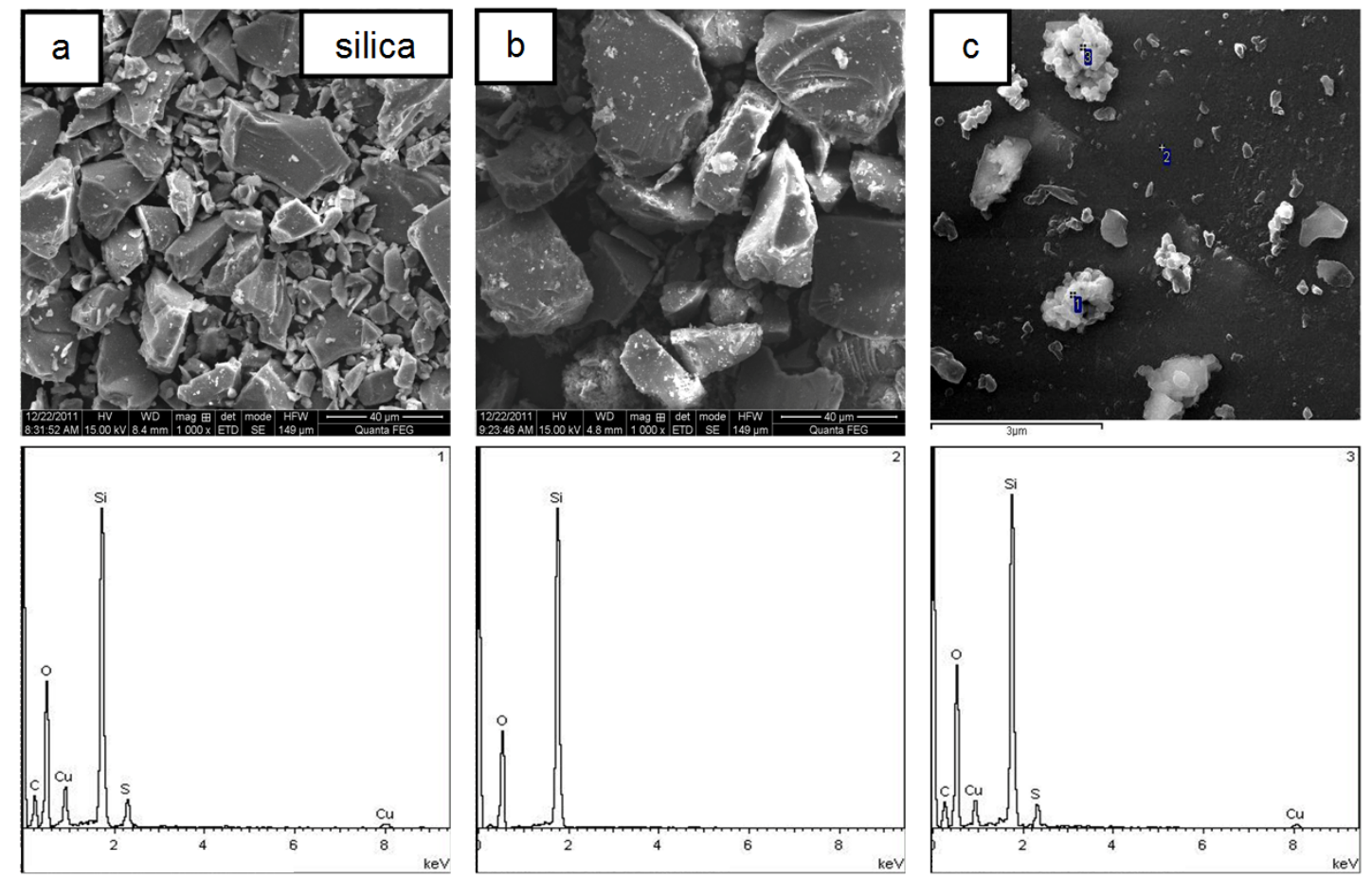

Figure 9. (a) SEM micrograph: silica in gypsum supersaturated solution at pH 9 (×1000); (b) SEM micrograph: silica adsorbed xanthate in gypsum supersaturated solution at pH $9(\times 1000)$; (c) SEM micrograph and EDS: silica adsorbed xanthate in gypsum supersaturated solution at pH $9(\times 20,000)$.

$10.86 \mathrm{wt} \%$, respectively. Cooper sulfide was generated and this consumed a portion of element sulfur from sphalerite surface as shown on Table 2 the element content comparison before and after the treatment. This is the main contributor to the element $\mathrm{S}$ concentration decrement.

It has been well established that activation of sphalerite using copper ions follows an ion exchange mechanism where the uptake of $\mathrm{Cu}(\mathrm{II})$ results in approximately $1: 1$ release of $\mathrm{Zn}^{2+}$ into the solution [7-9]. $\mathrm{Cu}(\mathrm{II})$ on the sphalerite surface is subsequently reduced to $\mathrm{Cu}(\mathrm{I})$ with the resulting oxidation of the surface sulfide. Collector molecules, such as xanthates, then react with the copper sulfide species formed on sphalerite surface, thus increasing the flotation response [10]. $\mathrm{Cu}(\mathrm{I})$-xanthate is the main product formed on sphalerite surface especially at low $\mathrm{pH}$ [9]. The uptake of copper and subsequent flotation of sphalerite depend on element impurity, sphalerite surface oxidation, concentration of copper and xanthate, activation time, pulp potential, and the slurry $\mathrm{pH}$, etc. 

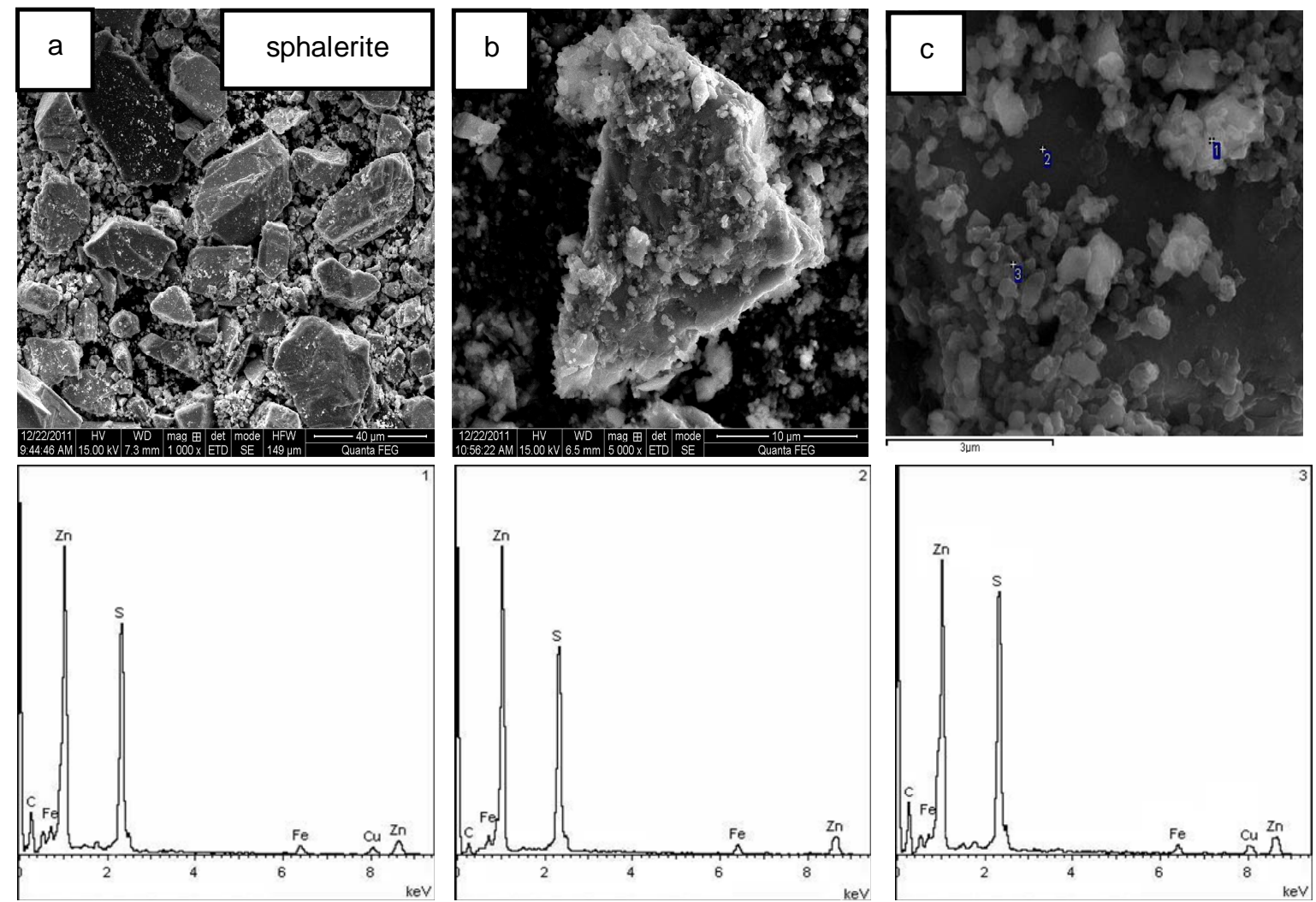

Figure 10. (a) SEM micrograph: sphalerite in the gypsum supersaturated solution at pH $9(\times 1000)$; (b) SEM micrograph: sphalerite adsorbed cooper sulfate and xanthate in the gypsum supersaturated solution at pH $9(\times 5000)$; (c) SEM micrograph and EDS: sphalerite adsorbed cooper sulfate and xanthate in the gypsum supersaturated solution at $\mathrm{pH} 9(\times 20,000)$.

\section{Conclusions}

Based on above discussion, following conclusions have been drawn for sphalerite and silica particles in solutions with different concentrations of calcium ions.

- Calcium ion concentration decreased until zero in the gypsum supersaturated solution, calcium carbonate supersaturated solution, and $1 \mathrm{mmol}$ potassium chloride solution.

- The interaction of mineral particles decreased with decreasing calcium ion concentration which was favorable for reagent selective adsorption. As a result, the higher the concentration of calcium ion, the more significant the interaction. The higher the concentration of calcium ions, the more likely the interactions occur.

- SEM micrograph and EDS shows evidence of a precipitate on the silica and sphalerite surface in gypsum supersaturated solution at $\mathrm{pH}$ 9. But a precipitate on sphalerite surface more than that of silica surface. This indicates that the xanthate adsorption ability is more strong on the sphalerite surface, it can be preferentially adsorbed on the sphalerite surface.

\section{Acknowledgements}

This work was financially supported by the National Natural Science Foundation of China (NSFC) (51074078). Special thanks are given to the research team for providing support to this study. The authors would also like to express their sincere thanks to Yingzi Wang for the surface measurement, scanning electron microscopy (SEM) and energy dispersive spectroscopy (EDS) analysis of the particles surface for scanning electron microscopy (SEM) and energy dispersive spectroscopy (EDS), and for some interesting discussions.

\section{REFERENCES}

[1] R. M. Beauchamp, J. W. Choung and Z. Xu, "Mineral Particle Interactions in Gypsum Supersaturated Process Water," In: Z. Xu and Q. Liu, Eds., Interfacial Phenomena in Fine Particle Technology: The 6th UBC-McGillUA International Symposium \& 45th Annual Conference of Metallurgists of CIM, Montreal, 2006.

[2] Z. Xu, J. Liu, J. Choung and Z. Zhou, "Electrokinetic Study of Clay Interactions with Coal in Flotation," International Journal of Mineral Processing, Vol. 68, No. 1-4, 2003, pp. 183-196. doi:10.1016/S0301-7516(02)00043-1

[3] J. Liu, Z. Zhou, Z. Xu and J. Masliyah, "Bitumen-Clay 
Interactions in Aqueous Media Studied by Zeta Potential Distribution Measurement," Journal of Colloid and Interface Science, Vol. 252, No. 2, 2002, pp. 409-418. doi:10.1006/jis. 2002.8471

[4] H. Ren, G. L. Song and F. F. Ji, "Effect on Electrochemical Properties for Calcium Ions in Silica-Sphalerite-Mixture (Silica:Sphalerite = 4:1) Systems," In: J. G. Wu, J. Yang, N. Nakagoshi, X. X. Lu and H. Xu, Eds., Natural Resources and Sustainable Development II: Part 2. 1st International Conference on Energy and Environmental Protection, Hohhot, 23-24 June 2012.

[5] R. J. Hunter, "Foundations of Colloid Science," Oxford Science Publications, New York, 1987, pp. 395-449.

[6] J. M. Vergouw, A. DiFeo, Z. Xu, et al., "An Agglomeration Study of Sulphide Minerals Using Zeta Potential and Settling Rate. Part II: Sphalerite/Pyrite and Sphalerite/ Galena," Minerals Engineering, Vol. 11, No. 7, 1998, pp. 605-614. doi:10.1016/S0892-6875(98)00045-4

[7] N. P. Finkelstein, "The Activation of Sulphide Minerals for Flotation: A Review," International Journal of Mineral Processing, Vol. 52, No. 2-3, 1997, pp. 81-120. doi:10.1016/S0301-7516(97)00067-7
[8] A. R. Gerson, A. G. Lange, K. E. Prince and R. S. C. Smart, "The Mechanism of Copper Activation of Sphalerite," Applied Surface Science, Vol. 137, No. 1-4, 1999, pp. 207-223. doi:10.1016/S0169-4332(98)00499-1

[9] S. R. Popov and D. R. Vucinic, "The Ethylxanthate Adsorption on Copper-Activated Sphalerite under FlotationRelated Conditions in Alkaline Media," International Journal of Mineral Processing, Vol. 30, No. 3-4, 1990, pp. 229-244. doi:10.1016/0301-7516(90)90017-S

[10] R. A. D. Pattrick, K. E. R. England, J. M. Charnock and J. F. M. Mosselmans, "Copper Activation of Sphalerite and Its Reaction with Xanthate in Relation to Flotation: An X-Ray Absorption Spectroscopy (Reflection Extended XRay Absorption Fine Structure) Investigation," International Journal of Mineral Processing, Vol. 55, No. 4, 1999, pp. 247-265. doi:10.1016/S0301-7516(98)00036-2

[11] A. P. Chandra and A. R. Gerson, "A Review of the Fundamental Studies of the Copper Activation Mechanisms for Selective Flotation of the Sulfide Minerals, Sphalerite and Pyrite," Advances in Colloid and Interface Science, Vol. 145, No. 1-2, 2009, pp. 97-110. doi:10.1016/j.cis.2008.09.001 